\title{
FORMULATION AND EVALUATION OF SELF-EMULSIFYING DRUG DELIVERY SYSTEM OF ETORICOXIB
}

\author{
SURENDRA SINGH SAURABH*, ROSHAN ISSARANI, NAGORI BP
}

Department of Pharmacy, Lachoo Memorial College of Science \& Technology (Autonomous), Pharmacy Wing, Jodhpur - 342 003, Rajasthan, India. Email: surendra.s.saurabh@gmail.com

Received: 21 March 2017, Revised and Accepted: 20 April 2017

\section{ABSTRACT}

Objective: In the present dissertation work, the aim was to prepare self-emulsifying drug delivery systems (SEDDS) of etoricoxib to improve its solubility with a view to enhance its oral bioavailability.

Methods: The prepared SEDDS was the concentrate of drug, oil, surfactants, and cosurfactant. The formulation was evaluated for various tests such as solubility, globule size, thermodynamic stability study, $\mathrm{pH}$ determination, ease of dispersibility, uniformity index, drug content, in-vitro release study, and in-vitro permeation study.

Results: The optimized formulation F6 showed drug release $(79.21 \pm 2.73 \%)$, droplet size $(0.546 \mu \mathrm{m})$. In vitro drug release of the F6 was highly significant $(\mathrm{p}<0.05)$ as compared to the plain drug.

Conclusion: All formulations of etoricoxib SEDDS were showed faster dissolution than plain drug ( $<<0.05$ ), mean bioavailability of etoricoxib increase in respect to the plain drug. The F6 can be further used for the preparation of various solid SEDDS formulations.

Keywords: Dissolution, Self-emulsifying drug delivery systems, Solubility study, Bioavailability.

(C) 2017 The Authors. Published by Innovare Academic Sciences Pvt Ltd. This is an open access article under the CC BY license (http://creativecommons. org/licenses/by/4. 0/) DOI: http://dx.doi.org/10.22159/ajpcr.2017.v10i7.18612

\section{INTRODUCTION}

Etoricoxib is a non-steroidal anti-inflammatory drug and has antiinflammatory, analgesic, and antipyretic activities. Etoricoxib is a selective cyclooxygenase 2 inhibitor, having anti-inflammatory and analgesic effects. It belongs to "BCS" class II and exhibits low \& variable oral bioavailability due to its poor aqueous solubility. Etoricoxib absorption through oral route is dissolution rate limited, and so, it requires enhancement in solubility and dissolution rate for increasing its oral bioavailability [1,16-20].

Self-emulsifying drug delivery systems (SEDDS) is a potential tool for improving the bioavailability of drugs with poor aqueous solubility [2]. SEDDS is a basically isotropic mixture of drug, oil, surfactant, and cosurfactant. They spontaneously form emulsion on dilution with water with little or no energy input. Being hydrophobic, etoricoxib may be easily incorporated in the oily phase of SEDDS. On the basis of abovementioned criteria, it is wise to prepare SEDDS of etoricoxib $[3,4]$.

In the present study, etoricoxib shall be formulated as SEDDS, and effect of different ratios of oil: smix (a mixture of surfactant and cosurfactant) in different concentrations was assessed on the release of etoricoxib.

\section{METHODS}

Etoricoxib was procured from Morepen Pvt. Ltd., Himachal Pradesh, as a gift sample. Soyabean oil (Ases Chemical Works, Jodhpur), Tween 80 (Loba Chemie Pvt. Ltd., Mumbai), Span 80 (Loba Chemie Pvt. Ltd., Mumbai), glycerol (Siphon Laboratories, Jodhpur), methanol (Loba Chemie Pvt. Ltd., Mumbai), sodium lauryl sulfate (SLS) (S.D. Fine Chemical Ltd., Mumbai), ethanol (Siphon Laboratories, Jodhpur), dialysis membrane (Hi-Media, Mumbai), Whatman's filter paper-42 (Whatman Int. Ltd, England), deionized water (In-house laboratory), and other chemical and solvents were of analytical grade/IP/equivalent grade and procured from laboratory.

\section{Formulation development of etoricoxib SEDDS Solubility studies}

The solubility of etoricoxib in various oils, surfactants, and cosurfactants was determined. $60 \mathrm{mg}$ of drug was taken in test tube and fixed volume of oil/ surfactant/cosurfactant was added until the drug dissolved completely[5-7].

\section{Construction of pseudo-ternary phase diagram}

The pseudo-ternary phase diagram was constructed by water titration method using oil, surfactant 1 , surfactant 2 , cosurfactant, drug, and water. The mixtures of oil, surfactant 1 , surfactant 2 , and cosurfactant at certain weight ratios were diluted with water in a drop by drop manner. These diagrams were constructed to identify the self-emulsifying region and to optimize the concentration of oil. The pseudo-ternary phase diagram was constructed after normalization of readings by the aid of CHEMIX school 3_60 software. For every phase diagram, a specific ratio of surfactant 1 : surfactant 2: cosurfactant (1:0.5:1, 1:1:1) was taken and homogenous mixture of oil \& drug was formed under the mixing by magnetic stirring. The various ratios of oil (containing drug):smix taken are 1:9, 2:8, 3:7, 4:6, 5:5, 6:4, 7:3, $8: 2,9: 1$, respectively. Then, every mixture was titrated with water and visually observed for flowability and phase clarity [8-11]. After the identification of a self-emulsifying region in the phase diagrams, the self-emulsifying formulations were selected at desired component ratios. The mixtures of selected surfactant and cosurfactant (Smix), i.e., Tween 80 , Span 80 , and glycerol were prepared in different ratios as presented in Table 1. 
Table 1: Ratios of Smix

\begin{tabular}{lllll}
\hline S.No. & $\begin{array}{l}\text { Volume of surfactant } \\
\mathbf{1}(\mathbf{m l}) \text { (Tween } \mathbf{8 0})\end{array}$ & $\begin{array}{l}\text { Volume of surfactant } \\
\mathbf{2}(\mathbf{m l}) \text { (Span 80) }\end{array}$ & $\begin{array}{l}\text { Volume of } \\
\text { cosurfactant (ml) (glycerol) }\end{array}$ & Ratio of Smix \\
\hline Smix 1 & 30 & 15 & 30 & $1: 0.5: 1$ \\
Smix 2 & 30 & 30 & 30 & $1: 1: 1$ \\
\hline
\end{tabular}

\section{Evaluation of etoricoxib SEDDS}

\section{Thermodynamic stability study of formulation}

The following cycles are carried out for study:

Heating-cooling cycle

The prepared etoricoxib SEDDS (undiluted) were kept at a temperature between $40^{\circ} \mathrm{C}$ and $45^{\circ} \mathrm{C}$ and kept at a temperature between $4^{\circ} \mathrm{C}$. This cycle is repeated 5 times [12-13].

\section{Centrifugation}

The prepared etoricoxib SEDDS (undiluted) were subjected to centrifugation at $3000 \mathrm{rpm}$ for 30 minutes and observed visually for phase separation [14].

Freeze-thaw cycle

The prepared etoricoxib SEDDS (undiluted) were kept at a temperature between $0^{\circ} \mathrm{C}$ and $4^{\circ} \mathrm{C}$ and then allowed to melt at room temperature [15].

\section{Homogeneity}

The prepared SEDDS were inspected visually for their color and homogeneity [21-25].

$\mathrm{pH}$ determination

The $\mathrm{pH}$ of the prepared SEDDS pre-concentrates was determined by using a digital $\mathrm{pH}$ meter [12].

Optical transparency

The optical transparency of SEDDS formulations was determined by using nepheloturbidometer at nephelometric turbidity units 100 [27].

\section{Globule size and shape}

The globules of the prepared formulations were observed under a trinocular upright microscope, and the size of globules was determined [27].

\section{Ease of dispersibility}

The prepared mefenamic acid pre-concentrates are diluted $(1 \mathrm{ml}$ in $100 \mathrm{ml}$ ) of water and then stirred on a magnetic stirrer at 50-100 rpm and visually observed for the ease of dispersibility and assigned following grades as shown in Table 2.

\section{Uniformity index}

Uniformity index is calculated to determine whether the prepared emulsion is monodispersed or polydispersed. It is the ratio of average weight diameter to average number diameter.

$$
\text { Uniformity index }=\frac{\text { Average weight diameter }(\mathrm{Dw})}{\text { Averagenumberdiameter(Dn) }}
$$

Where,

$$
\mathrm{D}_{\mathrm{w}}=\frac{\sum \mathrm{n}_{\mathrm{i}} \mathrm{d}_{\mathrm{i}}^{4}}{\sum \mathrm{n}_{\mathrm{i}} \mathrm{d}_{\mathrm{i}}^{3}} \text { and } \mathrm{D}_{\mathrm{n}}=\frac{\sum \mathrm{n}_{\mathrm{i}} \mathrm{d}_{\mathrm{i}}}{\sum \mathrm{n}_{\mathrm{i}}}
$$

$d_{i}=$ Mean diameter of particles; $n_{i}=$ Number of particles with diameter $d_{i}$.

If uniformity index is one, then the sample is monodispersed.
Table 2: Grades for ease of dispersibility

\begin{tabular}{lll}
\hline S.No. & Observation & Grade \\
\hline 1. & $\begin{array}{l}\text { Rapidly forming nanoemulsion (bluish ) } \\
\text { Rapidly forming microemulsion (blue to }\end{array}$ & $\mathrm{A}$ \\
transparent) & $\mathrm{B}$ \\
3. & $\begin{array}{l}\text { Fine milky emulsion formed in 2 min } \\
\text { Dull oily emulsion formed in>2 min }\end{array}$ & $\mathrm{C}$ \\
4. & $\begin{array}{l}\text { Poor or minimal emulsification with large oil } \\
\text { globules on surface }\end{array}$ & $\mathrm{E}$ \\
\hline
\end{tabular}

\section{Drug content}

$5 \mathrm{ml}$ of the prepared formulations were dissolved in $25 \mathrm{ml}$ of methanol in volumetric flask, and volume was made up to $100 \mathrm{ml}$ by methanol. The mixture is shaken well for 15-20 minutes and kept for $24 \mathrm{hrs}$. The solution was filtered through $0.45 \mu \mathrm{m}$ Whatman filter paper. The filtrate was assayed spectrophotometrically at $232.5 \mathrm{~nm}$ using a ultraviolet (UV)-visible spectrophotometer [28,29].

\section{In-vitro release study}

This study was done to determine release behavior of formulation using dialysis technique. Dialysis membrane (Hi-media) of pore size $2.4 \mathrm{~nm}$ and MWCO (Molecular weight cut-off) 12000-14000 was used for dissolution study. Before the diffusion studies, the dialysis membrane was soaked overnight in deionized water and for $1 \mathrm{hr}$ in $1 \%$ SLS solution. The hydrated membrane was used for dissolution study. One end of the dialysis membrane/tubing was tied with a thread, and $1 \mathrm{ml}$ of the SEDDS formulation and $1 \mathrm{ml}$ of dialyzing medium ( $1 \%$ SLS solution) were filled in the membrane. The other end of the membrane is also tied with thread and then allowed to rotate in the dialyzing medium at $50 \mathrm{rpm}$ using USP dissolution apparatus II. Samples were withdrawn at different time intervals and then after suitable dilution were analyzed. The volume of samples withdrawn was replaced with the fresh dialyzing medium. The diffusion study was performed at $37 \pm 2^{\circ} \mathrm{C}$ to different time intervals for $2 \mathrm{hrs}$ for formulated batch. Samples taken were then analyzed using UV spectrophotometer at $233.5 \mathrm{~nm}$ wavelength [30,31].

\section{In vitro permeation study}

Franz diffusion cell (with effective diffusion area $3.14 \mathrm{~cm}^{2}$ and $15 \mathrm{ml}$ cell volume) was used for the drug release studies. Egg membrane was used for the release study. The egg membrane was obtained from hen's egg (Gallus gallus; Genus: Gallus; Species: G. gallus) by keeping an egg in a $5 \mathrm{~N} \mathrm{HCl}$ solution $(200 \mathrm{ml})$. It was kept until the egg shell dissolved completely in $\mathrm{HCl}$ solution. Further, the egg was punctured, and egg yolk was discarded, and egg membrane was obtained, washed completely with de-ionized water and used.

Egg membrane was placed between donor and receptor compartments. In the receptor compartment of Franz diffusion cell, 1\% SLS solution was filled, and $1 \mathrm{ml}$ of SEDDS pre-concentrate with the same volume of $1 \%$ SLS solution was placed on the membrane through donor compartment. The release study was performed at $37 \pm 2^{\circ} \mathrm{C}$ to different time intervals for $5 \mathrm{hrs}$ for formulated batch. $1 \mathrm{ml}$ of recipient fluid was withdrawn at time intervals as shown in Table 15 and replaced with equal volume of fresh medium. Samples were analyzed spectrophotometrically at $233.5 \mathrm{~nm}$ [31].

\section{RESULTS AND DISCUSSION}

The self-emulsifying formulations consisted of oil, surfactant, cosurfactant, and drug should be a clear and monophasic liquid at ambient temperature when introduced into an aqueous phase and 
should have good solvent properties to allow presentation of the drug in solution. The solubility of the drug in various vehicles is presented in Table 3.

Amongst oils, soyabean oil provided the highest solubility, then other and amongst surfactants Tween 80 , Span 80 and amongst cosurfactants glycerol provided the highest solubility than other vehicles.

For the development of an SEDDS formulation, a right combination of low and high hydrophilic-lipophilic balance (HLB) surfactant is compulsory for the formulation of the stable microemulsion. Therefore, a high HLB surfactant (Tween 80) and low HLB surfactant (Span 80) were selected. Soyabean oil was found to be good with Tween 80 and Span 80; hence, it was selected for the optimal SEDDS formulation.

The pseudo-ternary phase diagram of the system comprising the surfactant 1 , surfactant 2 , cosurfactant, and the oily phase was constructed for Smix 1 and Smix 2 and is shown in Figs. 1 and 2. Pink area represents the region of self-emulsification. Within this area, a ternary mixture converts into fine oil in water emulsion with only gentle agitation. This is possible as the surfactant strongly localized to the surface of the emulsion droplet reduces interfacial free energy and provides a strong mechanical barrier to coalescence resulting in a thermodynamically spontaneous dispersion. Furthermore, cosurfactants increase interfacial fluidity by penetrating into the surfactant film creating void space among surfactant molecules.

On the basis of pseudo-ternary phase diagram study, following formulas have been derived from the area of the pseudo-ternary diagram for the two ratios 1:0.25:1 (F1, F2, F3), 1:1:1 (F4, F5, F6). The formulation composition of the etoricoxib SEDDS is presented in Table 4.

It has been found that none of the prepared etoricoxib SEDDS (undiluted) showed phase separation after subject to heating-cooling,

Table 3: Solubility of etoricoxib in various vehicles

\begin{tabular}{|c|c|c|c|}
\hline S.No. & Oil & $\begin{array}{l}\text { Volume of } \\
\text { vehicle }(\mathrm{ml})\end{array}$ & $\begin{array}{l}\text { Parts of vehicle } \\
\text { required to dissolve } \\
1 \text { part of etoricoxib }\end{array}$ \\
\hline 1. & Isopropyl myristate & 1 & 16.66 \\
\hline 2. & Castor oil & 1 & 16.66 \\
\hline 3. & Soyabean oil & 1 & 16.66 \\
\hline 4. & Oleic acid & 1 & 16.66 \\
\hline 5. & Olive oil & 1 & 16.66 \\
\hline 6. & Sunflower oil & 1 & 16.66 \\
\hline 7. & Groundnut oil & 1 & 16.66 \\
\hline 8. & Sesame oil & 1 & 16.66 \\
\hline 9. & Octanol & 1 & 16.66 \\
\hline 10. & Tween 80 & 1 & 16.66 \\
\hline 11. & Span 80 & 2 & 33.33 \\
\hline 12. & Tween 20 & 1 & 16.66 \\
\hline 13. & Span 20 & 2 & 33.33 \\
\hline 14. & Polyethylene glycol & 1 & 16.66 \\
\hline 15. & Propylene glycol & 2 & 33.33 \\
\hline
\end{tabular}

Table 4: Formulation composition of SEDDS of etoricoxib

\begin{tabular}{lllll}
\hline $\begin{array}{l}\text { Formulation } \\
\text { code }\end{array}$ & Ingredients & & & \\
\cline { 2 - 5 } & Etoricoxib (mg) & $\begin{array}{l}\text { Soyabean } \\
\text { oil (ml) }\end{array}$ & $\begin{array}{l}\text { Smix } \\
\mathbf{1}(\mathbf{m l})\end{array}$ & $\begin{array}{l}\text { Smix } \\
\mathbf{2}(\mathbf{m l})\end{array}$ \\
\hline F1 & 300 & 6.25 & 18.75 & - \\
F2 & 300 & 5 & 20 & - \\
F3 & 300 & 4.16 & 20.84 & - \\
F4 & 300 & 6.25 & - & 18.75 \\
F5 & 300 & 5 & - & 20 \\
F6 & 300 & 4.16 & - & 20.84 \\
\hline
\end{tabular}

SEDDS: Self-emulsifying drug delivery system centrifugation, and freeze-thaw cycling. The observations for phase separation after heating-cooling cycle, centrifugation, and freezethawing are shown in Tables 5-7, respectively.

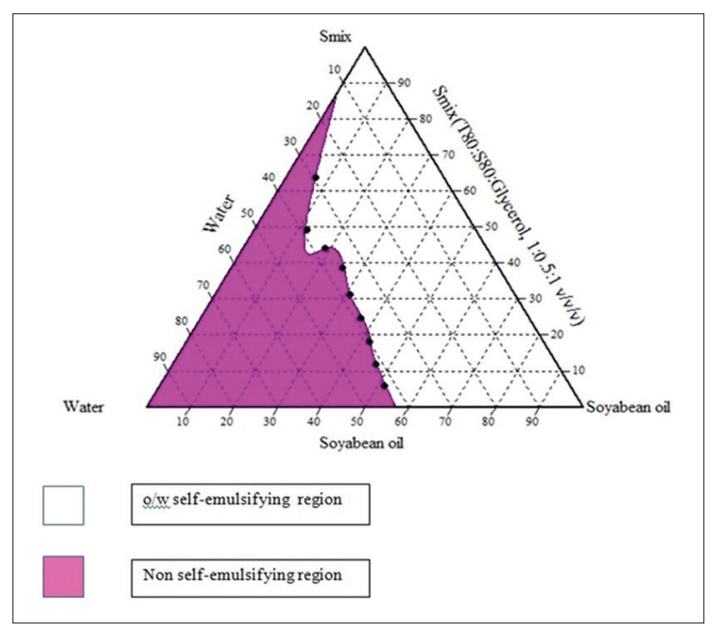

Fig. 1: Pseudoternary phase diagram for water:soyabean oil containing $100 \mathrm{mg}$ mefenamic acid:smix 1 (Smix 1 - Tween 80:Span 80:Glycerol - 1:0.5:1)

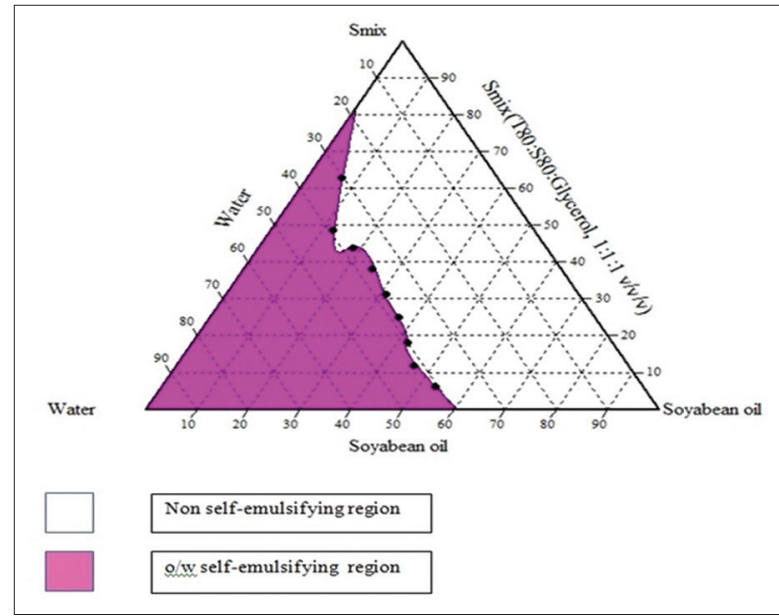

Fig. 2: Pseudoternary phase diagram for water:soyabean oil containing $100 \mathrm{mg}$ mefenamic acid:smix 2 (Smix 2 - Tween 80:Span 80:glycerol - 1:1:1)

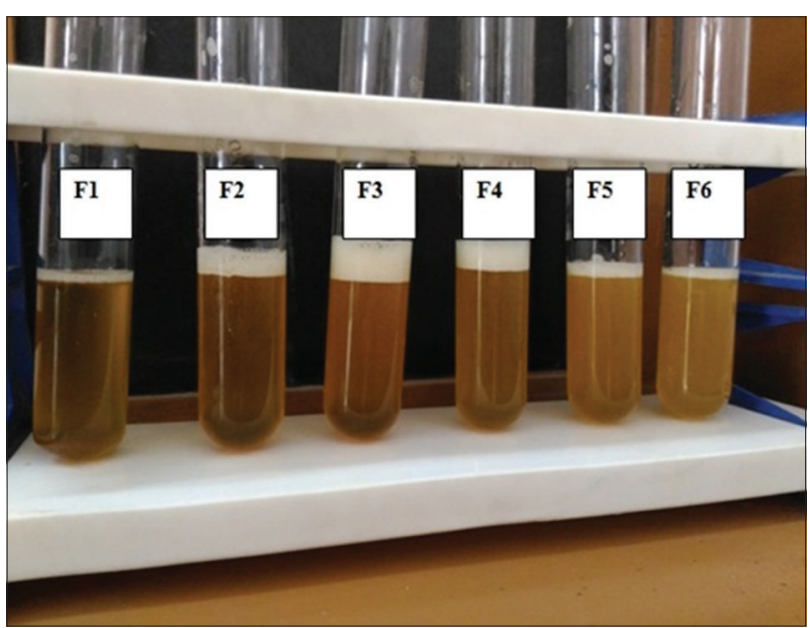

Fig. 3: Etoricoxib self-emulsifying drug delivery system 
Table 5: Observations for phase separation (heating-cooling cycle)

\begin{tabular}{|c|c|c|c|c|c|c|}
\hline S.No. & Formulation code & $\begin{array}{l}\text { Heating } \\
\text { temperature }\left({ }^{\circ} \mathrm{C}\right)\end{array}$ & $\begin{array}{l}\text { Cooling } \\
\text { temperature }\left({ }^{\circ} \mathrm{C}\right)\end{array}$ & Duration (minutes) & Number of cycles & $\begin{array}{l}\text { Observations for phase } \\
\text { separation }\end{array}$ \\
\hline 1. & $\mathrm{~F} 1$ & $40-45$ & 4 & 30 & 5 & No \\
\hline 2. & $\mathrm{~F} 2$ & $40-45$ & 4 & 30 & 5 & No \\
\hline 3. & F3 & $40-45$ & 4 & 30 & 5 & No \\
\hline 4. & $\mathrm{~F} 4$ & $40-45$ & 4 & 30 & 5 & No \\
\hline 5. & F5 & $40-45$ & 4 & 30 & 5 & No \\
\hline 6. & F6 & $40-45$ & 4 & 30 & 5 & No \\
\hline
\end{tabular}

Table 6: Observations for phase separation (after centrifugation)

\begin{tabular}{lllll}
\hline S.No. & Formulation code & rpm & Duration (min) & Observations \\
\hline 1. & F1 & $2000-3000$ & 30 & No phase separation \\
2. & F2 & $2000-3000$ & 30 & No phase separation \\
3. & F3 & $2000-3000$ & 30 & No phase separation \\
4. & F4 & $2000-3000$ & 30 & No phase separation \\
5. & F5 & $2000-3000$ & 30 & No phase separation \\
6. & F6 & $2000-3000$ & 30 & No phase separation \\
\hline
\end{tabular}

Table 7: Observations for phase separation (after freeze-thaw cycling)

\begin{tabular}{llllll}
\hline S.No. & Formulation code & $\begin{array}{l}\text { Freezing } \\
\text { temperature }\left({ }^{\circ} \mathbf{C}\right)\end{array}$ & Thawing temperature & Duration (hrs) & Number of cycles \\
\hline 1. & F1 & 0 & Room temperature & 18 & 1 \\
2. & F2 & 0 & Room temperature & 18 & 1 \\
3. & F3 & 0 & Room temperature & 18 & 1 \\
4. & F4 & 0 & Room temperature & 18 & 1 \\
5. & F5 & 0 & Room temperature & 18 & 1 \\
6. & F6 & 0 & Room temperature & 18 & No phase separation \\
\hline
\end{tabular}

Table 8: Determined pH of etoricoxib SEDDS

\begin{tabular}{lll}
\hline S.No. & Formulation code & Mean $\mathbf{p H} \pm$ SD* $^{*}$ \\
\hline 1. & F1 & $7.4 \pm 0.05$ \\
2. & F2 & $7.5 \pm 0.05$ \\
3. & F3 & $7.1 \pm 0.05$ \\
4. & F4 & $7.5 \pm 0.0$ \\
5. & F5 & $7.2 \pm 0.1$ \\
6. & F6 & $7.3 \pm 0.5$ \\
\hline
\end{tabular}

*Data indicate mean \pm SD ( $\mathrm{n}=3$ ). SD: Standard deviation, SEDDS: Self-emulsifying drug delivery system

Table 9: Transmittance of etoricoxib SEDDS

\begin{tabular}{lll}
\hline S.No. & Formulation code & Average transmittance \pm SD $^{*}$ \\
\hline 1. & $\mathrm{~F} 1$ & $87.33 \pm 2.08$ \\
2. & $\mathrm{~F} 2$ & $91 \pm 2$ \\
3. & $\mathrm{~F} 3$ & $81.66 \pm 4.04$ \\
4. & $\mathrm{~F} 4$ & $98.33 \pm 0.57$ \\
5. & $\mathrm{~F} 5$ & $90.66 \pm 0.57$ \\
6. & $\mathrm{~F} 6$ & $90.33 \pm 0.57$ \\
\hline *Data indicate mean \pm SD $(\mathrm{n}=3)$. SEDDS: Self-emulsifying drug delivery system
\end{tabular}

All SEDDS formulations were of yellow color, viscous preparation with an oily and homogeneous appearance as shown in Fig. 3.

The $\mathrm{pH}$ of all the pre-concentrates $\mathrm{F} 1$ to $\mathrm{F} 6$ was found to be in the range of 7.1-7.5, which lies in the normal pH range of the physiological fluids and would not produce any irritation, which is shown in Table 8.

The results show that the transmittance for F1, F2, F3, F4, F5, and F6 is $87.33 \pm 2.08,91 \pm 2,81.66 \pm 4.04,98.33 \pm 0.57,90.66 \pm 0.57$, and $90.33 \pm 0.57$, respectively, from which it can be inferred that F4, F5, and F6 are most
Table 10: Mean globule size of prepared formulations

\begin{tabular}{lll}
\hline S.No. & Formulation code & Mean globule size $(\boldsymbol{\mu m})$ \\
\hline 1. & F1 & 1.514 \\
2. & F2 & 1.481 \\
3. & F3 & 1.330 \\
4. & F4 & 0.543 \\
5. & F5 & 0.593 \\
6. & F6 & 0.546 \\
\hline
\end{tabular}

Table 11: Observations for ease of dispersibility

\begin{tabular}{lll}
\hline S.No. & Formulation code & Grade \\
\hline 1. & F1 & B \\
2. & F2 & B \\
3. & F3 & B \\
4. & F4 & B \\
5. & F5 & B \\
6. & F6 & B \\
\hline
\end{tabular}

transparent and it was due to low globule size of o/w emulsion which forms after dilution with water. The readings were taken in triplicate, and the average was calculated as shown in Table 9.

The formulation F4 was found to contain smallest mean globule size, whereas there is a slight increase in mean globule size of formulations F5 and F6. Furthermore, the globule size of F1 is largest. The mean globule size was calculated as shown in Table 10, and the optical microgram is presented in Fig. 4.

On the basis of the visual observations, it has been found that all the formulations of Smix 1 and Smix 2 are of B grade (Table 11), i.e., they rapidly form a transparent microemulsion. 
The uniformity index of F1, F2, F4, and F5 formulations found to be near 1 to 2; hence, these formulations can be considered as monodispersed. The observations of uniformity index are shown in Table 12.

The percentage content was found to range between $87.14 \pm 6.24 \%$ and $105.36 \pm 5.08 \%$ which is within the acceptable range of $100 \pm 15 \%$ which indicated the homogeneous distribution of drug throughout the SEDDS. The observations of drug content are shown in Table 13.

The release of etoricoxib from Smix 1 (F1, F2, F3) formulations is quite low as compared to all the formulations of Smix 2 (F4, F5, F6). The reason accountable for the above observation is the small mean globule

Table 12: Observations for uniformity index

\begin{tabular}{llll}
\hline $\begin{array}{l}\text { Formulation } \\
\text { code }\end{array}$ & $\begin{array}{l}\text { Average } \\
\text { weight } \\
\text { diameter }\end{array}$ & $\begin{array}{l}\text { Average } \\
\text { number } \\
\text { diameter }\end{array}$ & $\begin{array}{l}\text { Uniformity } \\
\text { index } \mathrm{D}_{\mathrm{w}} / \mathbf{D}_{\mathrm{n}}\end{array}$ \\
& $\mathrm{D}_{\mathrm{w}}=\frac{\sum \mathrm{n}_{\mathrm{i}} \mathrm{d}_{\mathrm{i}}^{4}}{\sum \mathrm{n}_{\mathrm{i}} \mathrm{d}_{\mathrm{i}}^{3}}$ & $\mathrm{D}_{\mathrm{n}}=\frac{\sum \mathrm{n}_{\mathrm{i}} \mathrm{d}_{\mathrm{i}}}{\sum \mathrm{n}_{\mathrm{i}}}$ & \\
\hline $\mathrm{F} 1$ & 1.597782 & 1.514184397 & 1.055209774 \\
$\mathrm{~F} 2$ & 1.49916069 & 1.481854839 & 1.011678506 \\
$\mathrm{~F} 3$ & 1.912771619 & 1.330508475 & 1.437624529 \\
$\mathrm{~F} 4$ & 1.053475936 & 0.54389313 & 1.936917159 \\
$\mathrm{~F} 5$ & 1.235 & 0.593155894 & 2.082083333 \\
$\mathrm{~F} 6$ & 1.069724771 & 0.546747967 & 1.956522629 \\
\hline
\end{tabular}

Table 13: Drug content of the prepared etoricoxib SEDDS

\begin{tabular}{lll}
\hline S.No. & Formulation code & Drug content \pm SD* \\
\hline 1. & F1 & $87.14 \pm 6.24$ \\
2. & F2 & $89.15 \pm 3.37$ \\
3. & F3 & $105.36 \pm 5.08$ \\
4. & F4 & $93.92 \pm 5.88$ \\
5. & F5 & $99.86 \pm 1.7$ \\
6. & F6 & $97.17 \pm 7.73$ \\
\hline
\end{tabular}

Data indicate mean \pm SD $(n=5)$. SD: Standard deviation, SEDDS: Self-emulsifying drug delivery system size of Smix 2 formulations as compared to Smix 1. Hence, it can be inferred that decreasing the globule size of the drug can increase the release of the drug and it might suggest that release rate of the drug can be controlled by regulating the mean globule size. Furthermore, it has been found that the release of etoricoxib is high in case of all the formulations (F1 to F6) as compared to the plain drug. All formulations of etoricoxib SEDDS were showed faster dissolution than plain drug

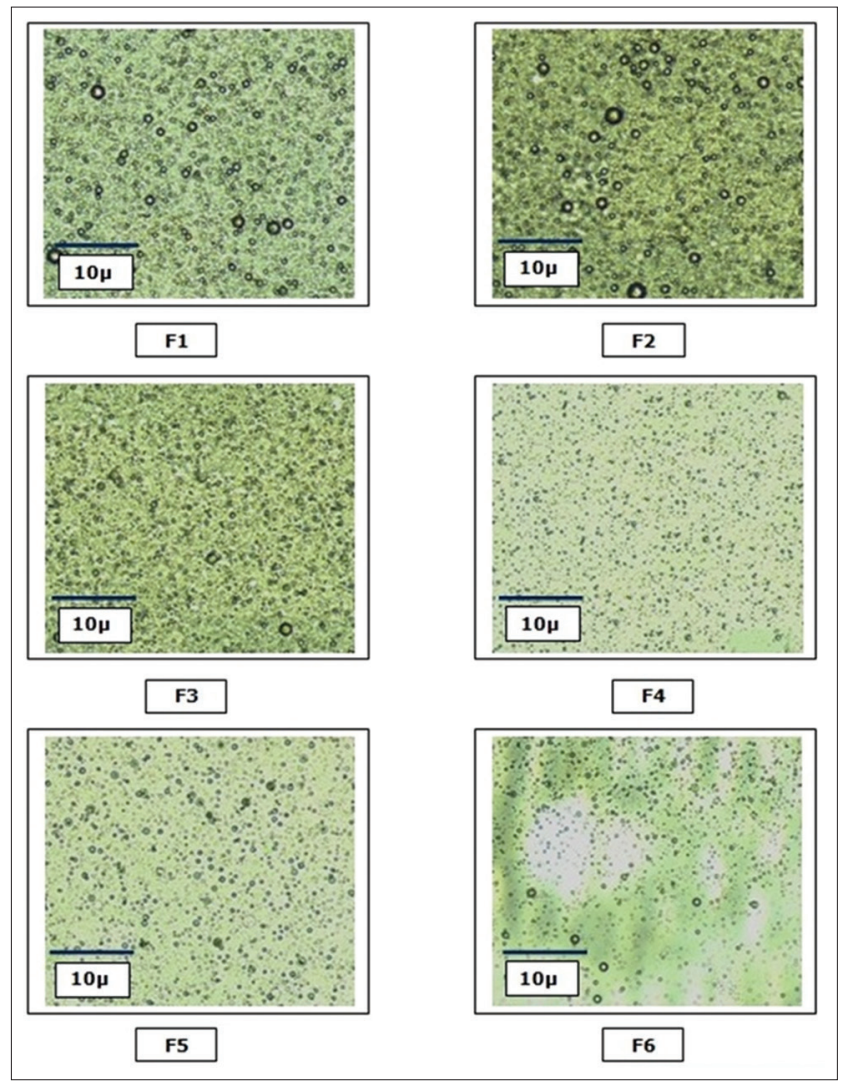

Fig. 4: Optical micrograph of etoricoxib self-emulsifying drug delivery system at $\times \mathbf{4 0}$ magnification

Table 14: In-vitro release of etoricoxib from prepared SEDDS pre-concentrates

\begin{tabular}{|c|c|c|c|c|c|c|c|}
\hline \multicolumn{8}{|c|}{$\%$ Cumulative drug release \pm SD } \\
\hline Time (minutes) & F1 & F2 & F3 & F4 & F5 & F6 & Plain drug \\
\hline 0 & 0 & 0 & 0 & 0 & 0 & 0 & 0 \\
\hline 15 & $8.25 \pm 6.80$ & $7.32 \pm 7.61$ & $9.50 \pm 5.51$ & $23.07 \pm 3.77$ & $22.53 \pm 8.32$ & $38.60 \pm 6.55$ & $1.03 \pm 5.71$ \\
\hline 30 & $26.32 \pm 8.60$ & $25.60 \pm 5.30$ & $22.53 \pm 8.32$ & $40.21 \pm 2.67$ & $35.28 \pm 6.41$ & $58.71 \pm 4.85$ & $2.84 \pm 4.33$ \\
\hline 45 & $31.67 \pm 4.71$ & $30.53 \pm 5.36$ & $35.28 \pm 6.41$ & $59.14 \pm 4.77$ & $44.64 \pm 9.43$ & $68.67 \pm 2.002$ & $4.15 \pm 7.12$ \\
\hline 60 & $47.64 \pm 6.52$ & $45.32 \pm 8.81$ & $44.64 \pm 9.43$ & $65.85 \pm 2.72$ & $59.28 \pm 10.21$ & $72.17 \pm 5.86$ & $8.96 \pm 2.01$ \\
\hline 120 & $51.42 \pm 5.66$ & $51.78 \pm 5.49$ & $59.28 \pm 10.21$ & $72.17 \pm 5.86$ & $70.85 \pm 13.48$ & $79.21 \pm 2.73$ & $10.51 \pm 1.29$ \\
\hline
\end{tabular}

Data indicate mean \pm SD $(n=3)$. SD: Standard deviation, SEDDS: Self-emulsifying drug delivery system

Table 15: In vitro release of etoricoxib through egg membrane

\begin{tabular}{|c|c|c|c|c|c|c|c|}
\hline \multicolumn{8}{|c|}{$\%$ In vitro release of etoricoxib through egg membrane \pm SD } \\
\hline Time (min) & F1 & F2 & F3 & F4 & F5 & F6 & Plain drug \\
\hline 0 & 0 & 0 & 0 & 0 & 0 & 0 & 0 \\
\hline 60 & $4.46 \pm 2.73$ & $5.75 \pm 0.59$ & $7.07 \pm 1.40$ & $5.92 \pm 1.03$ & $4.82 \pm 2.15$ & $7.0 \pm 0.97$ & 0 \\
\hline 120 & $9.07 \pm 3.90$ & $16.39 \pm 0.32$ & $16.28 \pm 5.57$ & $14.31 \pm 3.07$ & $14.6 \pm 4.10$ & $13.25 \pm 3.76$ & 0 \\
\hline 180 & $17.67 \pm 2.10$ & $17.46 \pm 1.51$ & $27.67 \pm 3.97$ & $32.71 \pm 2.76$ & $20.46 \pm 5.47$ & $32.0 \pm 1.6$ & 0 \\
\hline 240 & $22.42 \pm 2.01$ & $30.42 \pm 2.78$ & $41.75 \pm 3.38$ & $40.82 \pm 3.49$ & $29.10 \pm 2.64$ & $39.39 \pm 1.64$ & 0 \\
\hline 300 & $27.39 \pm 1.66$ & $34.75 \pm 7.62$ & $43.53 \pm 1.45$ & $50.39 \pm 6.55$ & $40.89 \pm 3.02$ & $53.964 \pm 10.13$ & 0 \\
\hline
\end{tabular}

*Data indicate mean \pm SD (n=3). SD: Standard deviation 
$(\mathrm{p}<0.05)$. However, F6 formulation of Smix 2 showed best performance (\%R120: 79.21 \pm 2.73 ) in enhancing solubility and dissolution rate of etoricoxib suggesting an optimum ratio of oil and Smix. The observations of dissolution study are shown in Table 14.

The release of the etoricoxib from all etoricoxib SEDDS formulations was observed, and the SEDDS formulation can be ranked in the following descending order: F6 > F4 > F3 > F5 > F2 > F1 where the amounts of the etoricoxib released after 5 hrs were $53.964 \pm 10.13$, $50.39 \pm 6.55,43.53 \pm 1.45,40.89 \pm 3.02,34.75 \pm 7.62$, and $27.39 \pm 1.66$, respectively. At the $5^{\text {th }} \mathrm{hr}$, the higher drug release was observed with formulation F6. The reason accountable for the above observation is the small mean globule size F6 formulations as compared to all other formulations. The observations of in vitro release study are shown in Table 15. All formulations of etoricoxib SEDDS were showed faster dissolution than plain drug $(\mathrm{p}<0.05)$, mean bioavailability of etoricoxib increase in respect to the plain drug.

\section{CONCLUSION}

A SEDDS formulation of a poor water soluble drug, etoricoxib was formulated for oral administration. The formulation F6 was found to be the optimized formulation on the basis of results of pseudo-ternary phase diagram, dissolution study, in vitro drug release, droplet size. The optimized formulation showed rapid self-emulsification in aqueous media. In vitro drug release of the F6 was highly significant $(\mathrm{p}<0.05)$ as compared to the plain drug. The results from the study show the utility of SEDDS to enhance solubility and dissolution of sparingly soluble compounds such as etoricoxib. The F6 can be further used for the preparation of various solid SEDDS formulations.

\section{ACKNOWLEDGMENTS}

Authors are profusely thankful to Lachho Memorial College of Science and Technology, Jodhpur, staff for their constant and perennial support and friends Vikas Mehta, Rekha Singh Saurabh, Mamta Choudhary, and Gaurav Jain.

\section{REFERENCES}

1. Thakkar H, Patel B, Thakkar S. A review on techniques for oral bioavailability enhancement of drugs. Int J Pharm Sci Rev Res 2010;4(3):203-24

2. Mistry RB, Sheth NS. A review: Self emulsifying drug delivery system. Int J Pharm Pharm Sci 2011;3(2):238.

3. Kohli K, Chopra S, Dhar D, Arora S, Khar RK. Self-emulsifying drug delivery systems: An approach to enhance oral bioavailability. Drug Discov Today 2010;15(21-22):958-65.

4. Zupancic O, Grießinger JA, Rohrer J, Pereira de Sousa I, Danninger L, Partenhauser A, et al. Development, in vitro and in vivo evaluation of a self-emulsifying drug delivery system (SEDDS) for oral enoxaparin administration. Eur J Pharm Biopharm 2016;109:113-21.

5. Agrawal AG, Kumar A, Gide PS. Self emulsifying drug delivery system for enhanced solubility and dissolution of glipizide. Colloids Surf B Biointerfaces 2015;126:553-60.

6. Patel AR, Vavia PR. Preparation and in vivo evaluation of SMEDDS (self-microemulsifying drug delivery system) containing fenofibrate. AAPS J 2007;9(3):E344-52.

7. Kadu PJ, Kushare SS, Thacker DD, Gattani SG. Enhancement of oral bioavailability of atorvastatin calcium by self-emulsifying drug delivery systems (SEDDS). Pharm Dev Technol 2011;16(1):65-74.

8. Kanchan K. Self Emulsifying Drug Delivery System for A Curcuminoid Based Composition. United States Patent 20110294900; 2011

9. Shanmugam S, Baskaran R, Balakrishnan P, Thapa P, Yong CS, Yoo BK. Solid self-nano emulsifying drug delivery system (S-SNEDDS) containing phosphatidylcholine for enhanced bioavailability of highly lipophilic bioactive carotenoid lutein. Eur J Pharm Biopharm 2011;79(2):250-7
10. Gasperlin M, Zvonar A, Berginc K. Microencapsulation of self micro emulsifying system: Improving solubility and permeability of furosemide. Int J Pharm 2009;8(3):151-8.

11. Mader K, Klein S, Abdalla A. A new self-emulsifying drug delivery system for poorly soluble drugs: Characterization, in vitro digestion and incorporation into solid pellets. Eur J Pharm Sci 2008;35(5):457-64

12. Shukla JB, Jani GK, Omri AW. Formulation and evaluation of oral self micro emulsifying drug delivery system of candesartan cilexetil. Int J Pharm Pharm Sci 2016;8(5):238-43.

13. Date AA, Nagarsenker MS. Design and evaluation of selfnanoemulsifying drug delivery systems (SNEDDS) for cefpodoxime proxetil. Int J Pharm 2007;329(1-2):166-72.

14. Kang BK, Lee JS, Chon SK, Jeong SY, Yuk SH, Khang G, et al. Development of self-microemulsifying drug delivery systems (SMEDDS) for oral bioavailability enhancement of simvastatin in beagle dogs. Int J Pharm 2004;274(1-2):65-73.

15. Nazzal S, Smalyukh II, Lavrentovich OD, Khan MA. Preparation and in vitro characterization of a eutectic based semisolid selfnanoemulsified drug delivery system (SNEDDS) of ubiquinone: Mechanism and progress of emulsion formation. Int $\mathrm{J}$ Pharm 2002;235(1-2):247-65

16. Yanli L, Yuanyuan D, Sufeng M. Etoricoxib Dispersible Tablets and Preparation Method Thereof. WIPO Patent Application Number: 201510005409; 2015.

17. Chowdary KP, Enturi V, Pallavi TV. Formulation development of etoricoxib tablets by wet granulation and direct compression methods employing starch phosphate - A new modified starch. Pharm Lett 2011;3(6):163-72.

18. Chowdary KP, Rao KS, Madhuri D. Formulation and evaluation of etoricoxib tablets employing cyclodextrin - Poloxamer 407 - PVPK30 inclusion complexes. Int J Appl Biol Pharm Technol 2011;2(4):43-8.

19. Thakre A, Bhople A, Jaiswal S. Formulation and development of oral fast dissolving tablet of etoricoxib. Pharm Lett 2012;4(4):1169-82.

20. Chauhan B, Shimpi S, Paradkar A. Preparation and characterization of etoricoxib solid dispersions using lipid carriers by spray drying technique. AAPS PharmSciTech 2005;6(3):E405-12.

21. Patel SN, Patel DN, Patel CN. Self emulsifying drug delivery system. J Glob Pharm Technol 2010;2(2):29-37.

22. Singh K, Sharma M, Gandhi K. Recent approaches in self emulsifying drug delivery system. Int J Pharm Sci Res 2012;3(11):4192-201.

23. Nawale RB, Salunke PB, Jadhav AB. Self emulsifying drug delivery system: A review. J Pharm Sci Res 2015;6(8):3198-208.

24. Sharma V, Singh J, Gill B, Harikumar SL. SMEDDS: A novel approach for lipophilic drugs. J Pharm Sci Res 2012;3(6):2441-50.

25. Goyal U, Gupta A, Rana AC, Aggarwal G. Self micro emulsifying drug delivery system: A method for enhancement of bioavailability. J Pharm Sci Res 2012;3(1):66-79.

26. Attama AA, Nkemnele MO. In vitro evaluation of drug release from self micro-emulsifying drug delivery systems using a biodegradable homolipid from Capra hircus. Int J Pharm 2005;304(1-2):4-10.

27. Deshmukh SR, Bakhle SS, Upadhye K, Dixit GR. Formulation and evaluation of solid self-emulsifying drug delivery system of gliclazide. Int J Pharm Pharm Sci 2016;8(11):144-51.

28. Jaiswal P, Aggarwal G, Harikumar SL, Singh K. Development of self-microemulsifying drug delivery system and solid-selfmicroemulsifying drug delivery system of telmisartan. Int $\mathrm{J}$ Pharm Investig 2014;4(4):195-206.

29. Meena AK, Sharma K, Kandaswamy M, Rajagopal S, Mullangi R. Formulation development of an albendazole self-emulsifying drug delivery system (SEDDS) with enhanced systemic exposure. Acta Pharm 2012;62(4):563-80.

30. Qi X, Wang L, Zhu J, Hu Z, Zhang J. Self-double-emulsifying drug delivery system (SDEDDS): A new way for oral delivery of drugs with high solubility and low permeability. Int J Pharm 2011;409(12):245-51.

31. Feng N, Zhang P, Liu Y, Xu J. Preparation and evaluation of selfmicro emulsifying drug delivery system of oridonin. Int J Pharm 2007;9(3):269-76

32. Abdalla A, Mäder K. Preparation and characterization of a self-emulsifying pellet formulation. Eur J Pharm Biopharm 2007;66(2):220-6 